\title{
Energy Absorption Capacity of Reinforced Concrete Beam-Column Connections, with Ductility Classes Low
}

\author{
Mohammadamin Azimi, Azlan Bin Adnan, Mohd Hanim Osman*, Abdul Rahman Bin Mohd Sam, Iman \\ Faridmehr, Reza Hodjati
}

\author{
Department of Structure \& Material, Faculty of Civil Engineering, Universiti Teknologi Malaysia (UTM), Skudai, Johor Bahru, \\ Malaysia \\ *Corresponding author: mhaim@utm.my
}

Received January 13, 2014; Revised February 28, 2014; Accepted March 04, 2014

\begin{abstract}
Once the behaviour of reinforced concrete moment resisting frame structures is investigated, it is concluded that the performance of beam column connections is not satisfactory. In order to understand the complex mechanisms and satisfactory behaviour of beam column connections, lots of investigations have been done. The most critical zone in reinforced concrete moment resisting frames would be the beam column connection. The behaviour of beam column connection once it is subjected to large forces during earthquakes has a great impact on the response of the structure. The shear failure has a brittle nature which is not a desirable structural performance during earthquakes. Two new types of shear reinforcements design are introduced in this study for the purpose of reaching a higher performance and material capacity for the connection and hence, the structure. These two shear reinforcement designs working simultaneously with other reinforcement systems and concrete have a better performance compared to that of conventional methods. The first specimen is made according to conventional method of design as control specimens in conformance with Euro code EC2 \& EC8. The second specimen introduces a continued shear resistance system against discontinued conventional shear resistance system (stirrups) which is called "Single Square Spring Shear Resistance System" (SSSSRS). The third specimen possesses two continued square spring systems twisting together and making a parallel system called "Double Square Spring Shear Resistance System" (DSSSRS). A comparison was made between the performances of the improved shear reinforcement systems of beam-column connections against the control specimens. It was concluded that a lower deflection along with higher energy absorption was achieved for "Single Square Spring Shear Resistance System" (SSSSRS) and "Double Square Spring Shear Resistance System" (DSSSRS) compared to control specimens.
\end{abstract}

Keywords: beam-column connection, continued system, Single Square Spring Shear Resistance System, Double Square Spring Shear Resistance System, moment resisting frame

Cite This Article: Mohammadamin Azimi, Azlan Bin Adnan, Mohd Hanim Osman, Abdul Rahman Bin Mohd Sam, Iman Faridmehr, and Reza Hodjati, "Energy Absorption Capacity of Reinforced Concrete BeamColumn Connections, with Ductility Classes Low." American Journal of Civil Engineering and Architecture, vol. 2, no. 1 (2014): 42-52. doi: 10.12691/ajcea-2-1-5.

\section{Introduction}

A number of advantages for continued shear resistance systems to reinforce beam-column connections exist including easy installation, high strength, application of higher steel capacity, better load and stress transferring and flexibility. Changing the discontinued shear resistance system (stirrups) to continued shear resistance system would be a very effective way of improving the shear performance of the beam-column connections in concrete structures. Shear failure suppression would be the primary objective of joint design. This may lead to application of huge amounts of joint shear reinforcement which may impose difficulties on construction process [1-10]. A complex mechanism is described for force transfer within beam column connection of a rigid frame in case of a seismic event [14] including transfer of shear and bond in the joint core and bending in beams and columns. The continuity of the spring shape would be a positive characteristic in transferring loads and stresses through the reinforcing system more efficiently than conventional system (discontinued stirrups) and consequently, having better connection shear behaviour. The installation of this system is done in two orthogonal directions of the connection which are the critical zones of the connection. Several researchers have made many experimental investigations regarding the behaviour of exterior beam column joint $[9,13]$. Incorporation of headed reinforcement in joint region has been studied by Wallace, et.al [12]. This paper is dedicated to the introduction of two new types of shear reinforcing systems of the beamcolumn connections in concrete structures. Firstly, instead of using the conventional shear resistance system which is discontinued elements (stirrups), a single square spring element is applied which acts as a continued shear reinforcement. Secondly, double square spring elements 
possessing two square spring members that twist together and are installed in system as parallel are used in the connection instead of the conventional shear reinforcing system. Some assumptions have been made in the system for the purpose of avoiding the increase in the steel weight of the connection. An equal thickness is chosen for the stirrups and the spring of the "Single Square Spring Shear Resistance System” (SSSSRS) where an equal distance was chosen for the distance between stirrups and pitch of the spring. Also, an equal thickness is chosen for the stirrups and the springs of the "Double Square Spring Shear Resistance System” (DSSSRS) which twist together to make a parallel system and simultaneously the distance between stirrups is chosen half of the pitch of springs as shown in Figure 1 and Figure 2.

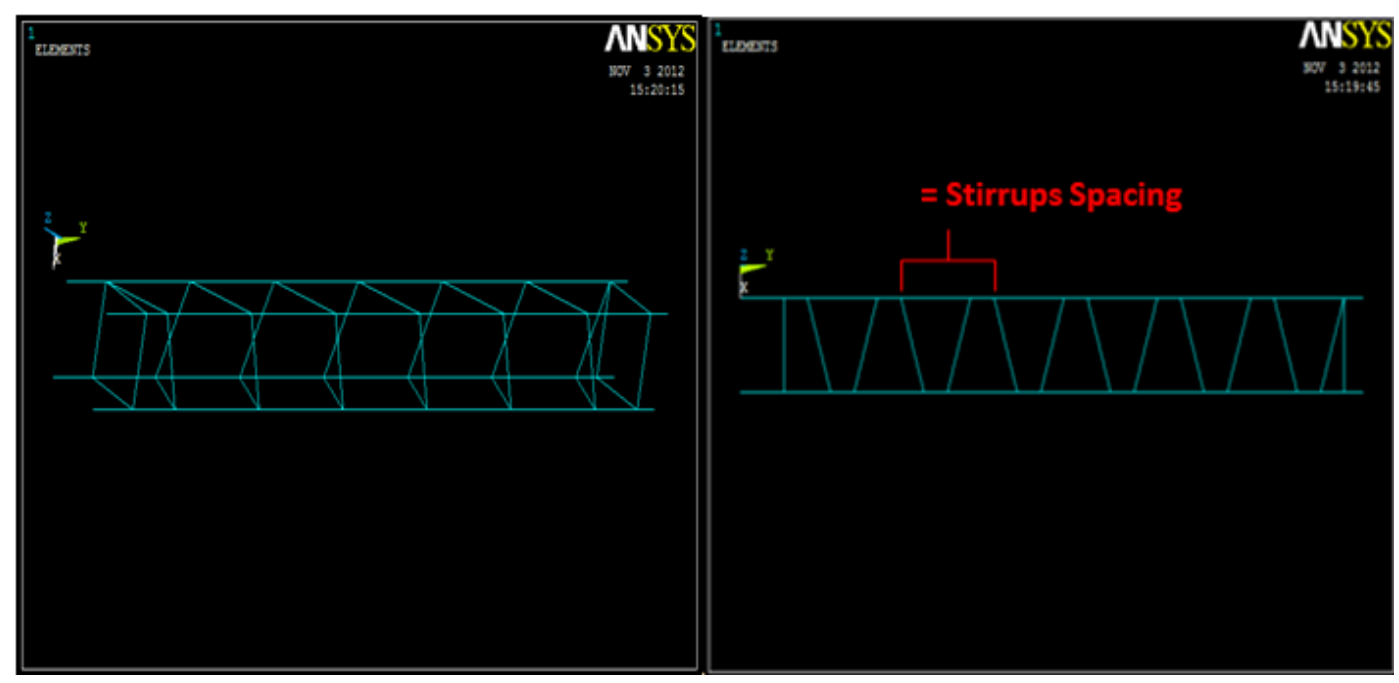

Figure 1. Single Square Spring Shear Resistant System (SSSSRS)

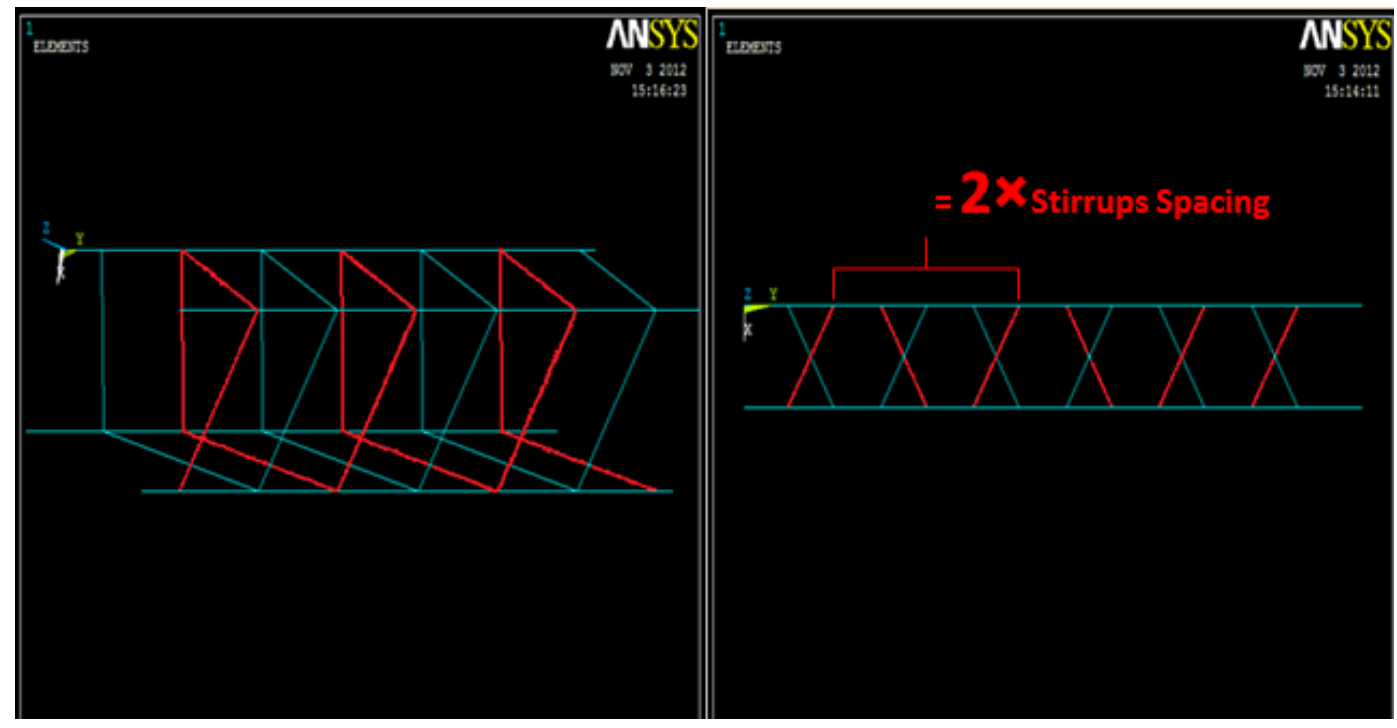

Figure 2. Double Square Spring Shear Resistant System (DSSSRS)

The assumption for connections is the analysis of reinforced concrete moment resisting frames is that they are rigid. Previous earthquake records show catastrophic failures regarding the design of beam column connections. In case of seismic events, the high demand imposed by the adjoining flexural members (beams and columns) when their inelastic capacities are required to dissipate seismic energy could be paired with the poor design practice of beam column connections. Even if the design of the other structural members is done appropriately in conformance with the design requirements, the entire structure could be put at risk due to unsafe detailing and design of the connection region. Provision of enough ductility in earthquake design is a leading factor in seismic energy dissipation of the structure. The spread of the plastic hinges which are the inelastic rotations spread over definite regions is an important issue in design of reinforced concrete members. In case of inelastic deformations, a beyond elastic range behaviour is expected from actual material properties and therefore, formation of damages are obvious in plastic range. In case of seismic design, formation of damages is preferred in beams compared to columns.

It is noteworthy to mention that all properties including cross sections, materials, loading, length and thickness of bars and longitudinal bars were taken the same for all three specimens. This indicates the focus would be on shear reinforcements and their replacement with the two new continued systems. In order to understand the performance mechanism of the behaviour of improved shear resistant system in reinforced concrete beam-column connection specimens improved with continues shear 
reinforcing system, the finite element modelling software ANSYS was used for modelling the reinforced concrete beam-column connections. Both ends of columns were hinged during the analysis process. The free end of the cantilever beam was subjected to a controlled static load. The part of the column within the deepest beam depth that frames into the column is the definition of the connection. Three types of connections namely interior connection, exterior connection and corner connection could be identified in a moment resisting frame. An interior connection is introduced as a connection in which four beams frame into the vertical faces of a column. An exterior connection is defined as a connection in which a vertical face of a column is framed into by one beam and two other beams are framed into the connection from perpendicular directions. Finally, a corner connection is defined as a connection in which two adjacent vertical faces of a column are framed into by two beams. A deeper understanding of the seismic behaviour of these connections seems necessary due to the severity of forces and high demand on these connections performance. Complex mechanisms are developed by these forces including bond and shear within the connection. Based on design requirements, sufficient capacity for beam-column connections must be provided for the purpose of sustaining the maximum flexural resistance for all the attached members. The complex mechanism of force transfer inside the beam-column connection of a rigid frame involves shear and bond stress transfer in the connection along with bending in beams and columns during seismic events. The forces inserted on connection under lateral load are demonstrated in Figure 3.

Shear failure suppression must be the primary objective of connection design which leads to application of a noticeable amount of connection shear reinforcement that hinders the construction process to a great extent. The complications of the existing seismic code details regarding reinforced concrete structures in high seismic zones make the installation and pouring of concrete in the beam-column connection regions troublesome and challenging. Therefore, a new continued type of shear resistant system, different from discontinued conventional shear resistance system, is introduced in this paper so that the ductility capacity of the connection is increased without any need for conventional reinforcement increase and the construction difficulties in the connection area are avoided.

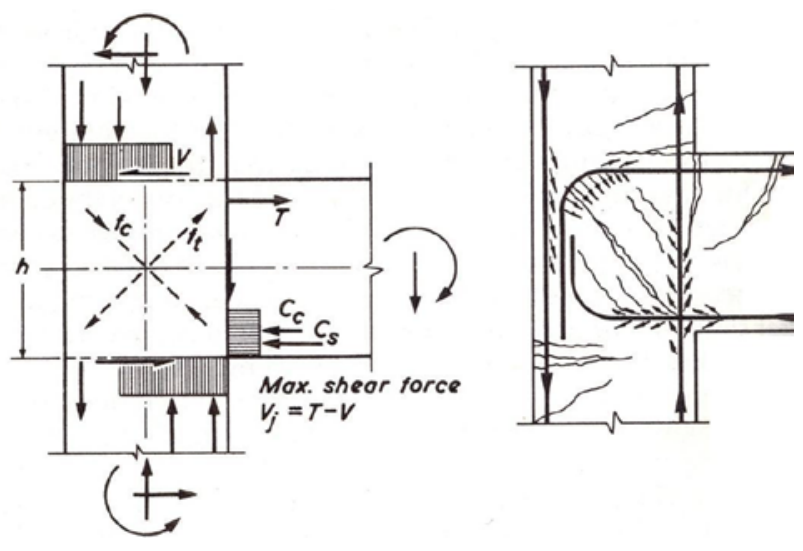

Figure 3. Force action in connections

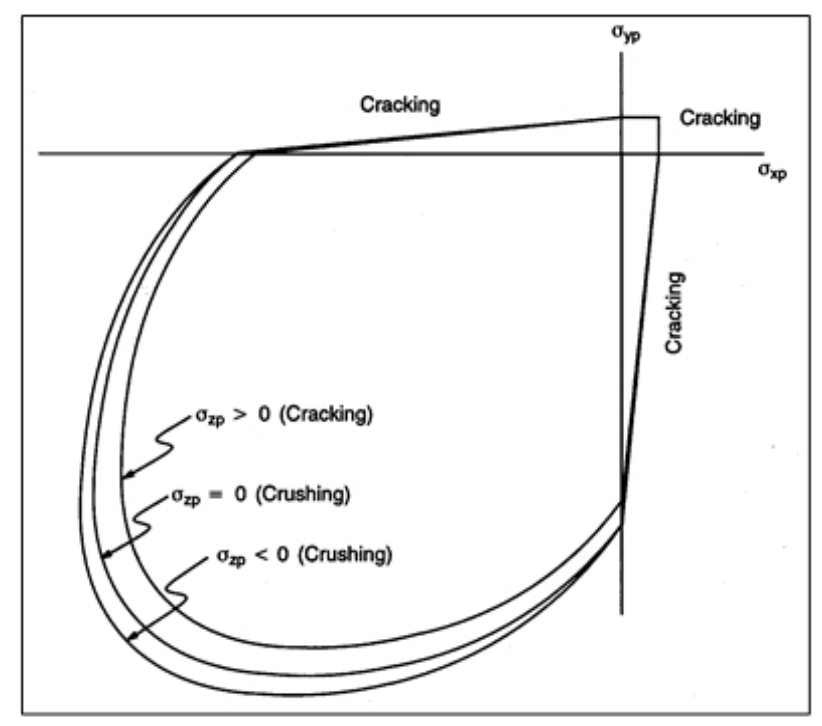

Figure 4. 3-D failure surface for concrete [5]

\section{Finite Element Modelling}

The finite element software ANSYS was used to model and analyse the improved beam-column connection using two new continued shear reinforced system in this paper. Hence, the modelling of 3 exterior reinforced concrete beam-column connection specimens was done using ANSYS software. The physical behaviour of complicated engineering systems is simulated and predicted using the finite element method (FEM) as a principal way. This is due to the common acceptance of commercial finite element analysis (FEA) software like ANSYS among researchers and engineers. Therefore, the 3 exterior beamcolumn connections namely the one with conventional shear reinforcing system design based on EC2 as the control specimen (CS), the Single Square Spring Shear Reinforcing System specimen (SSSSRS) and finally Double Square Shear Reinforcing System (DSSSRS) were modelled and analysed in ANSYS software. The design of the specimens was done in conformance with Euro code EC2, EC8. An equal dimension of 200mm X 200mm was chosen for both column and beam sections. Furthermore, failure prediction for concrete materials is one capability of this model and cracking and also, crushing failure modes are both considered in this model. For the purpose of defining a failure surface for the concrete, two input strength parameters namely ultimate uniaxial tensile and compressive strengths are required. Hence, a failure criterion for concrete as a result of a multi-axial stress state could be found [5]. Figure 4 shows a threedimensional failure surface for concrete.

\subsection{Finite Element Modelling of Steel Reinforcement}

For the purpose of modelling steel reinforcement in reinforced concrete for finite element models [6], three techniques are applied that are illustrated in Figure 5: the discrete model, the embedded model, and the smeared model. The element types incorporated in finite element study are shown in Table 1 . The Required parameters for defining the material models are shown in Table 2. 


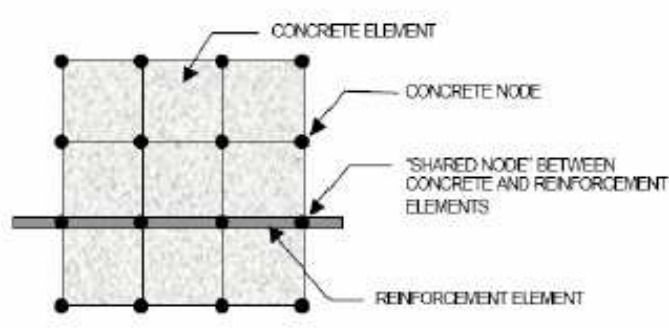

(a)

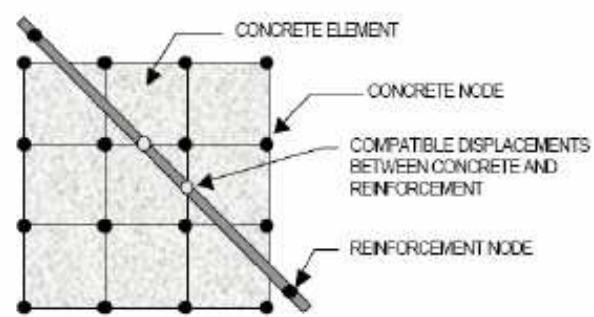

(b)

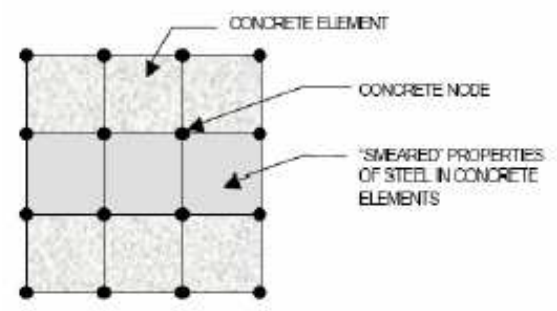

(c)

Figure 5. Models for Reinforcement in Reinforced Concrete [6,9]: (a) discrete; (b) embedded; and (c) smeared

Table 1. Element Types for Working Model

\begin{tabular}{|c|c|}
\hline Material Type & ANSYS Element \\
\hline Concrete & Solid65 \\
\hline Steel Reinforcement & Link8 \\
\hline
\end{tabular}

Table 2. Material Models for the Calibration Model

\begin{tabular}{|c|c|c|c|}
\hline Element Type & \multicolumn{3}{|c|}{ Material Properties } \\
\hline & \multicolumn{3}{|c|}{ Linear Isotropic } \\
\hline & EX & 3604974.865 & \\
\hline & PRXY & 0.25 & \\
\hline & \multicolumn{3}{|c|}{ Multilinear Isotropic } \\
\hline & & Strain (in/in) & Stress (psi) \\
\hline & Point1 & 0.00049931 & 1800 \\
\hline & Point2 & 0.00065 & 2158.06 \\
\hline & Point3 & 0.00080 & 2552.24 \\
\hline & Point4 & 0.001 & 2996.43 \\
\hline & Point5 & 0.0012 & 3347.11 \\
\hline & Point6 & 0.0014 & 3609.99 \\
\hline & Point7 & 0.0016 & 3794.94 \\
\hline & Point8 & 0.0018 & 3913.71 \\
\hline Solid65 & Point9 & 0.002 & 3978.22 \\
\hline & Point10 & 0.0022 & 3999.57 \\
\hline & Point11 & 0.002219 & 4000 \\
\hline & Point12 & 0.003 & 4000 \\
\hline & \multicolumn{3}{|c|}{ Concrete } \\
\hline & ShrCf-Op & 0.3 & \\
\hline & ShrCf-C1 & 1 & \\
\hline & UnTensSt & 474.34 & \\
\hline & UnCompSt & -1 & \\
\hline & BiCompSt & 0 & \\
\hline & HydroPs & 0 & \\
\hline & BiCompSt & 0 & \\
\hline & UnTensSt & 0 & \\
\hline & TenCrFac & 0 & \\
\hline & \multicolumn{3}{|c|}{ Linear Isotropic } \\
\hline & $\mathrm{EX}$ & $29,000,000 \mathrm{psi}$ & \\
\hline & PRXY & 0.3 & \\
\hline Link8 & \multicolumn{3}{|c|}{ Bilinear Isotropic } \\
\hline & Yield Stress & 60,000 psi & \\
\hline & Tangent Modulus & $2,900 \mathrm{psi}$ & \\
\hline
\end{tabular}

Linear isotropic and multi-linear isotropic material properties are required by the Solid65 element for the concrete to be properly modelled. The von Mises failure criterion along with other models is used by the multi- linear isotropic material for the purpose of defining the concrete failure [5]. EX is the modulus of elasticity of the concrete $(E c)$, and PRXY is the Poisson's ratio $(\mu)$. The following equation is used for calculation of the modulus of elasticity,

$$
E_{c}=57000 \sqrt{f_{c}^{\prime}}
$$

with $f^{\prime} c$ value equal to 4,000 psi. Poisson's ratio was taken as 0.25 . Furthermore, the following equations were used to find the compressive uniaxial stress-strain relationship for the concrete model and also calculate the multi-linear isotropic stress-strain curve for the concrete (Mac Gregor, 1992):

$$
\begin{gathered}
f=\frac{E_{c} s}{1+\left(\frac{\varepsilon}{\delta_{0}}\right)^{2}} \\
\varepsilon_{0}=\frac{2 f^{\prime} c}{E_{c}} \\
E_{c}=\frac{f}{\delta}
\end{gathered}
$$

Where; $f=$ stress at any strain $\varepsilon$, psi, $\varepsilon=$ strain at stress $f, \varepsilon$ $0=$ strain at the ultimate compressive strength, $f^{\prime} c$ the multi-linear isotropic stress-strain implemented requires the first point if the curve to be defined by the user. It might satisfy Hook's Law;

$$
E=\frac{\sigma}{\delta}
$$

In order for the nonlinear solution algorithm to be converged, the multi-linear curve is incorporated. The stress-strain relationship applied to this study is shown in Figure 6 which is based on the findings of Kachlakev, et al. [7]. Point 1, defined as ' 0.45 f'c, in MacGregor Nonlinear model curve is found in the linear range (Equation 4). 
Calculation of other points is done from Equation 2 with $\varepsilon 0$ obtained from Equation 3. Definition of the last point at $f c^{\prime}$ and $\varepsilon 0=0.003$ in./in. shows the traditional crushing strain for unconfined concrete.

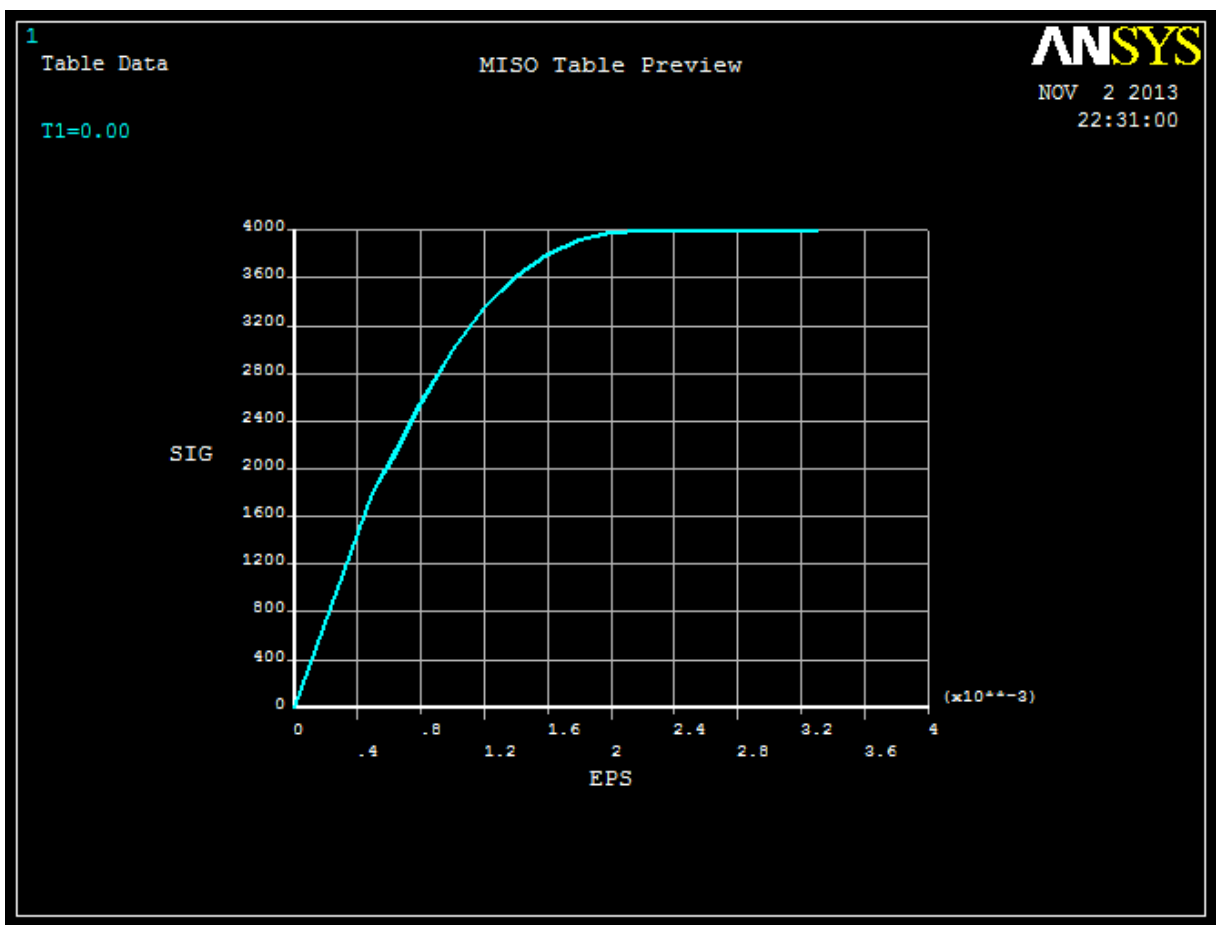

Figure 6. Uniaxial Stress-Strain Curve

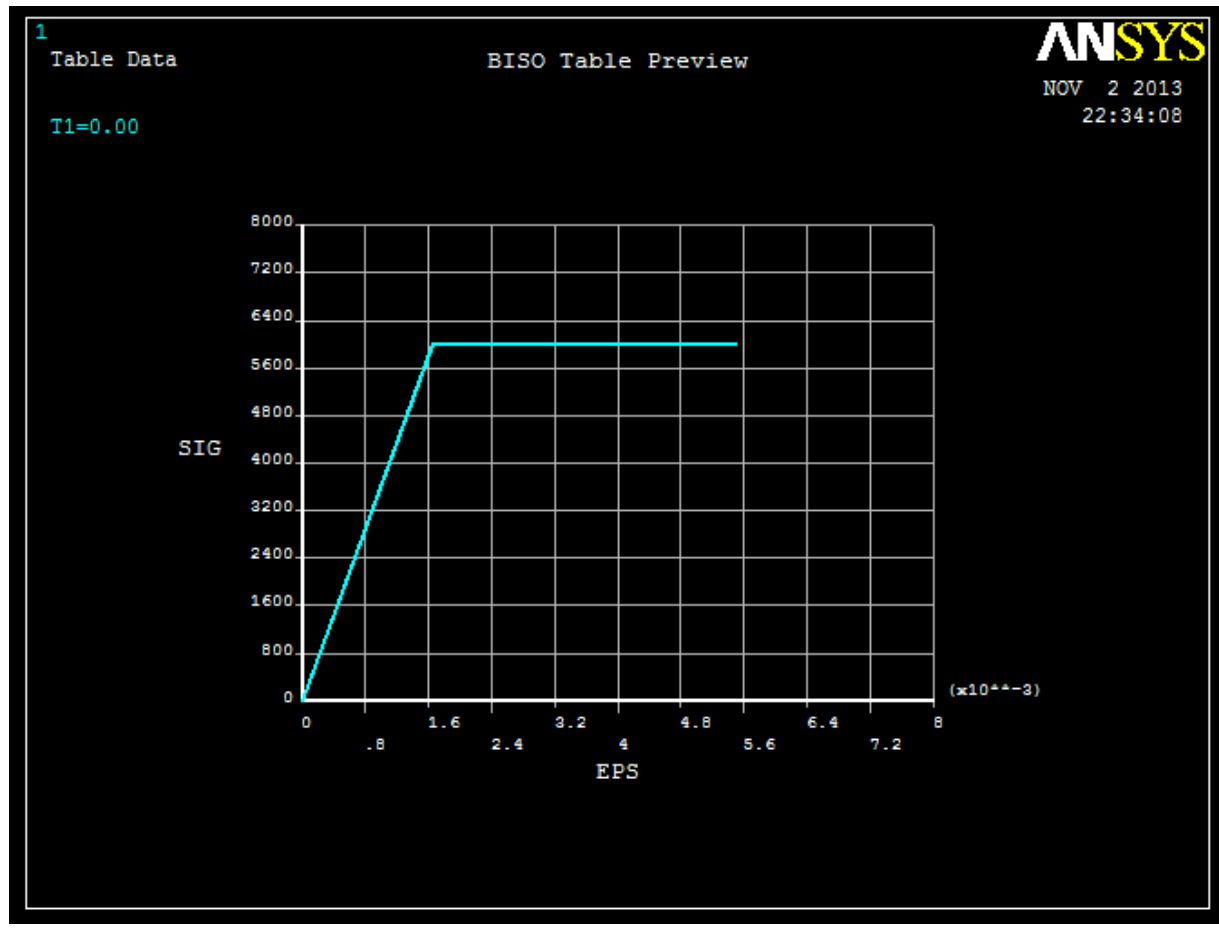

Figure 7. Idealized Stress-Strain Curve of Reinforcing Steel

\subsection{Non-linear Modelling of the Beam- Column Connections}

Figure 8.a, Figure 8.b and Figure 8.c show the beamcolumn connection to be analysed which is made of a cantilever part and a column part. Both the column and the beam had an equal cross section of $200 \mathrm{~mm}$ x $200 \mathrm{~mm}$ while the overall column length was $1200 \mathrm{~mm}$ and the cantilevered portion length was $600 \mathrm{~mm}$. The design of the control specimens was done conventionally. The Euro
Code was used for the purpose of conventional design of the specimen. Similar details have been considered for the two other specimens (modified shear resistance system) compared to conventional specimen except for the shear resistance system which was modified and became continued as opposed to the discontinued shear reinforcing system (stirrups). 4 numbers of $6-\mathrm{mm}$ diameter rods for the columns and 2 numbers of $8 \mathrm{~mm}$ diameter rods in top and 2 numbers of $6 \mathrm{~mm}$ diameter rods in bottom part (tension and compression zones) for the beam were used as reinforcement. $6 \mathrm{~mm}$ diameter bars with the spacing of 
$260 \mathrm{~mm}$ centre to centre were used as lateral ties in the column using a conventional design. Vertical stirrups of 6 $\mathrm{mm}$ diameter bar at $260 \mathrm{~mm}$ centre to centre were used in the beam. Some provisions in beams regarding the development lengths of the tension and compression rods were made. For the "Single Square Spring Shear Resistance System" specimen (SSSSRS), one continued, 6-mm bar having the same thickness with stirrups in conventional specimen was used instead of the lateral ties in the column and beam. Furthermore, a $260-\mathrm{mm}$ pitch is provided for this square spring equal to that of the distance between stirrups in conventional specimen. For the "Double Square Spring Shear Resistance System" specimen (DSSSRS), two continued, 6-mm bars having the same thickness with stirrups in conventional specimen were used instead of the lateral ties in the column and beam. Still, a 520-mm pitch twice the distance between stirrups in conventional specimen was used for this specimen. Figure 8 (a), Figure 8 (b) and Figure 8(c) illustrate the typical views of the ANSYS model of the specimens.

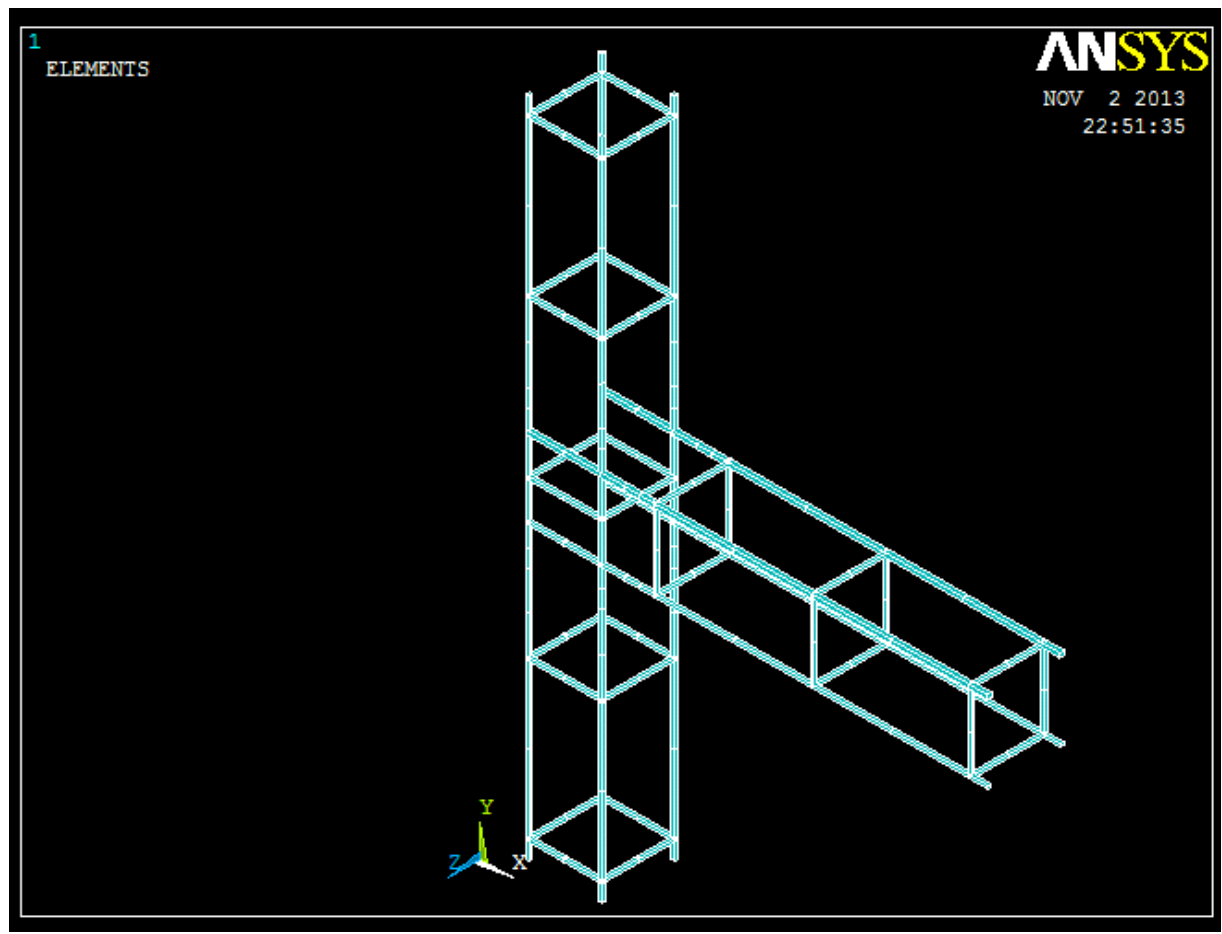

Figure 8a. Typical View of ANSYS Model for conventional design according to Euro code for Low Ductility Classes

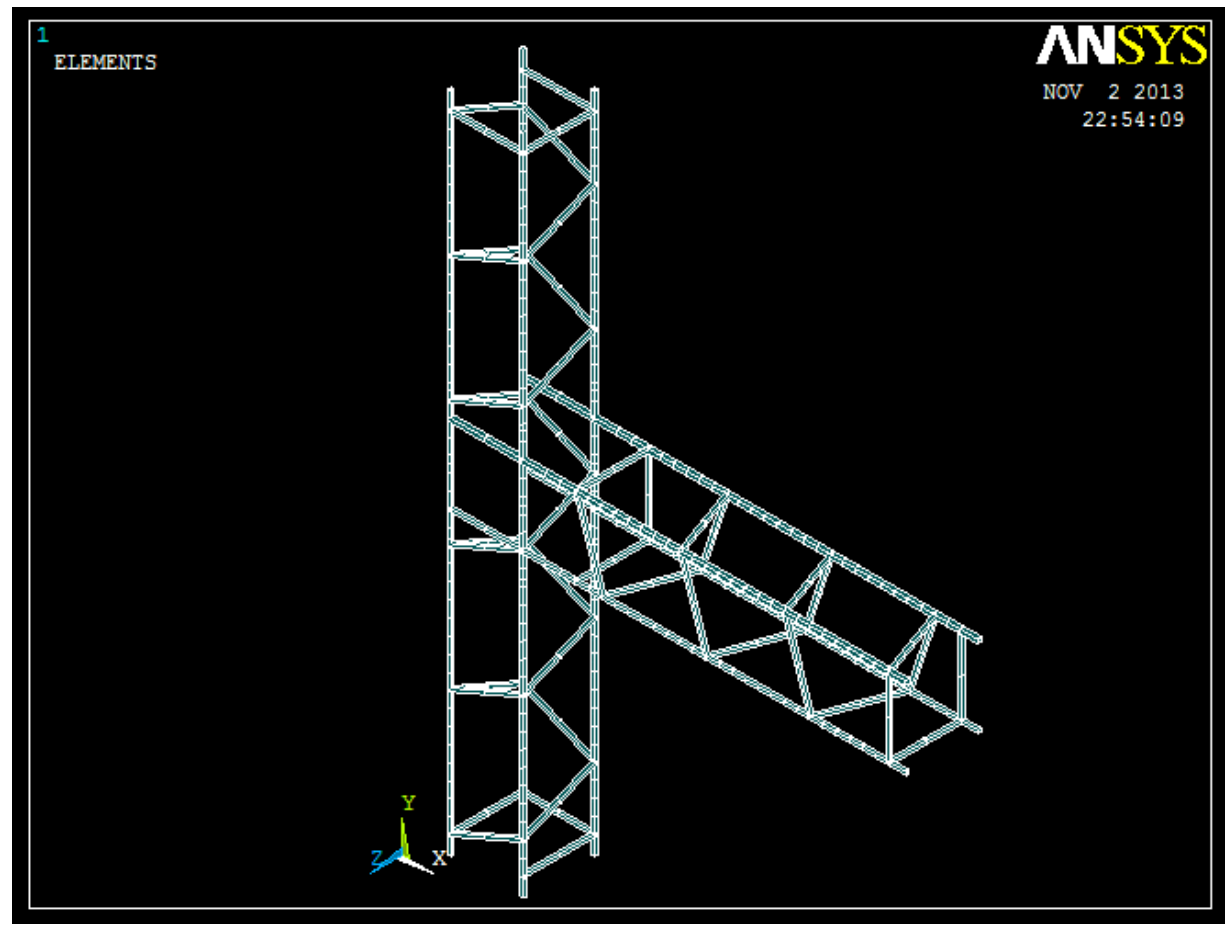

Figure 8b. Typical View of ANSYS Model for Single Square Spring Shear Resistant System (SSSSRS) 


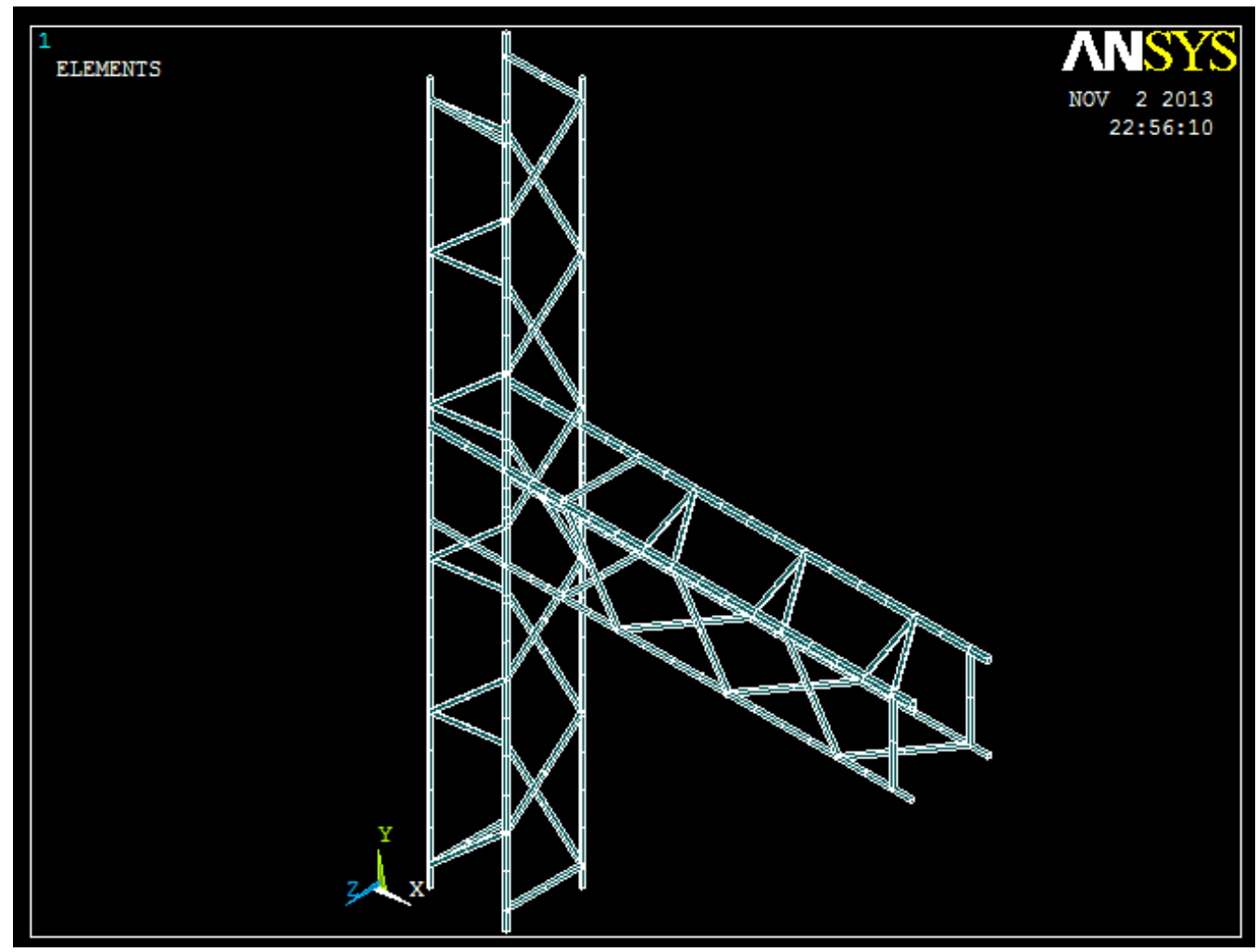

Figure 8c. Typical View of ANSYS Model for Double Square Spring Shear Resistant System (DSSSRS)

Meshing of control and improved specimens was done using ANSYS software. Both column ends were hinged. The Solid 65 element was incorporated to mesh the concrete. Modelling of the reinforcement was done incorporating Link 8 element. The free end of the cantilever beam was subjected to a static load at a regular load interval of $5 \mathrm{kN}$ for both the control and improved reinforced concrete beam-column connection models. Then, a comparison was made between the performance of the improved beam-column connection specimens and the control beam-column connection specimen. The meshing of the control and improved specimens is illustrated in Figure 9 (a), Figure 9 (b) and Figure 9 (c).

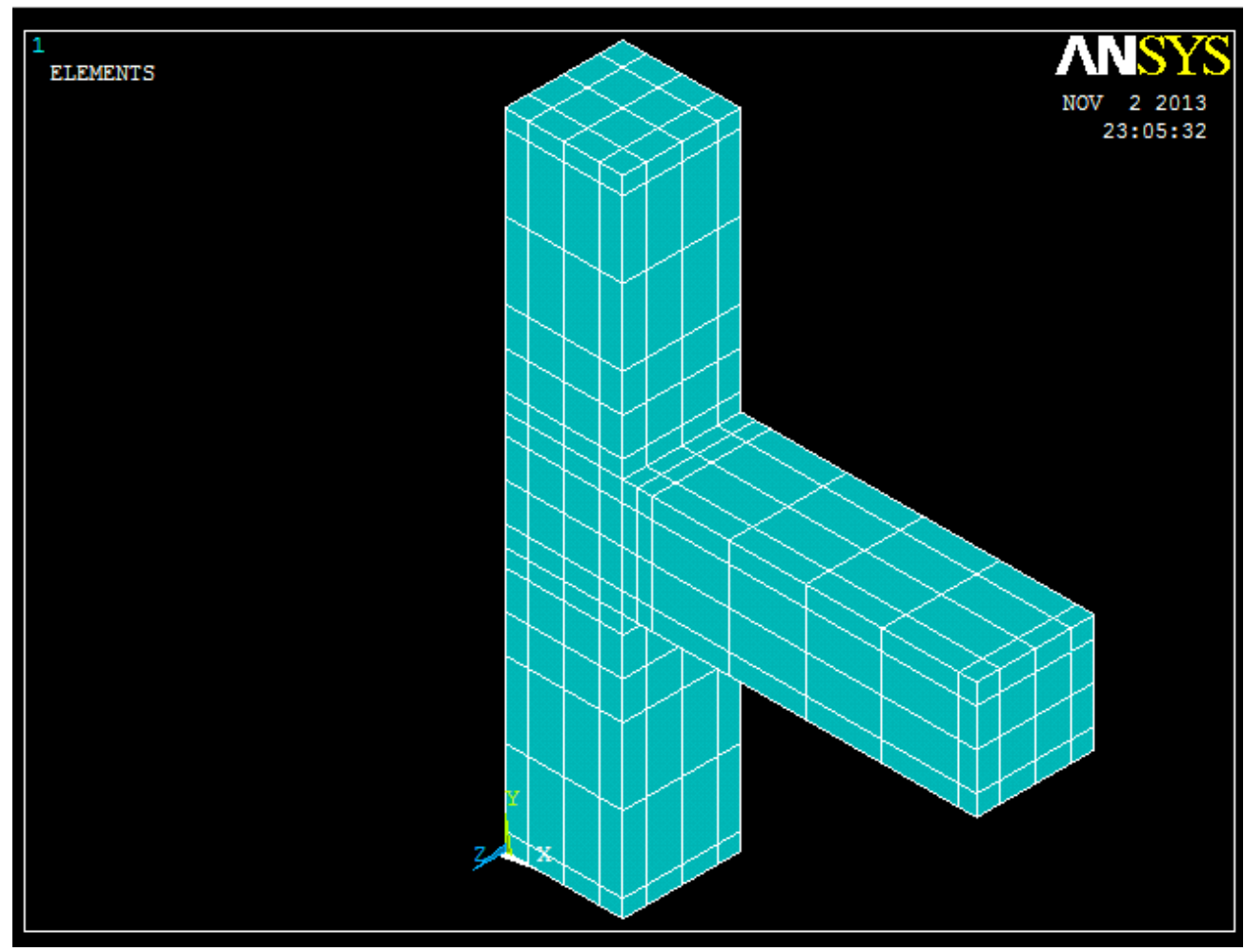

Figure 9a. Typical meshed Control Specimen conventional design 


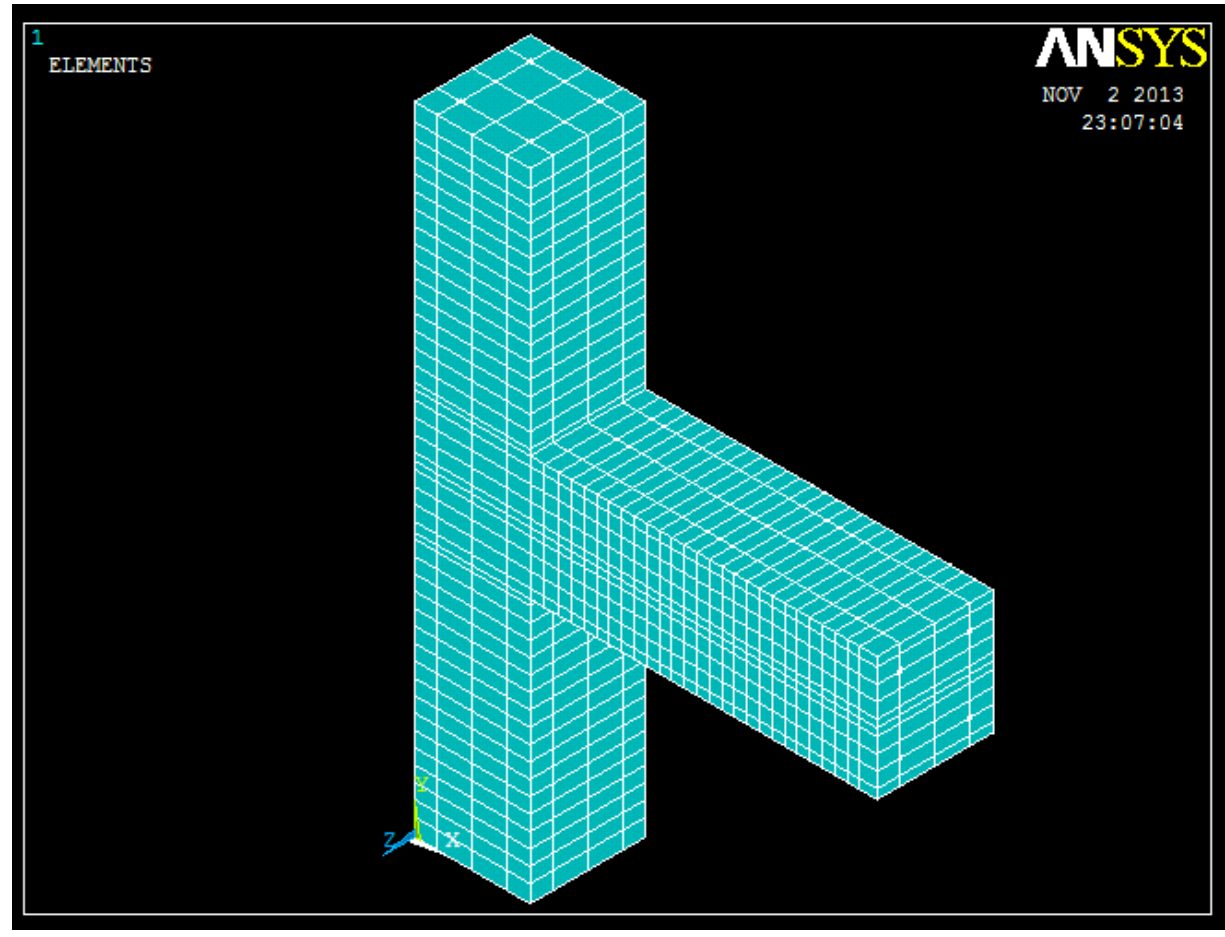

Figure 9b. Typical meshed Single Square Spring Shear Resistant System (SSSSRS) Specimen

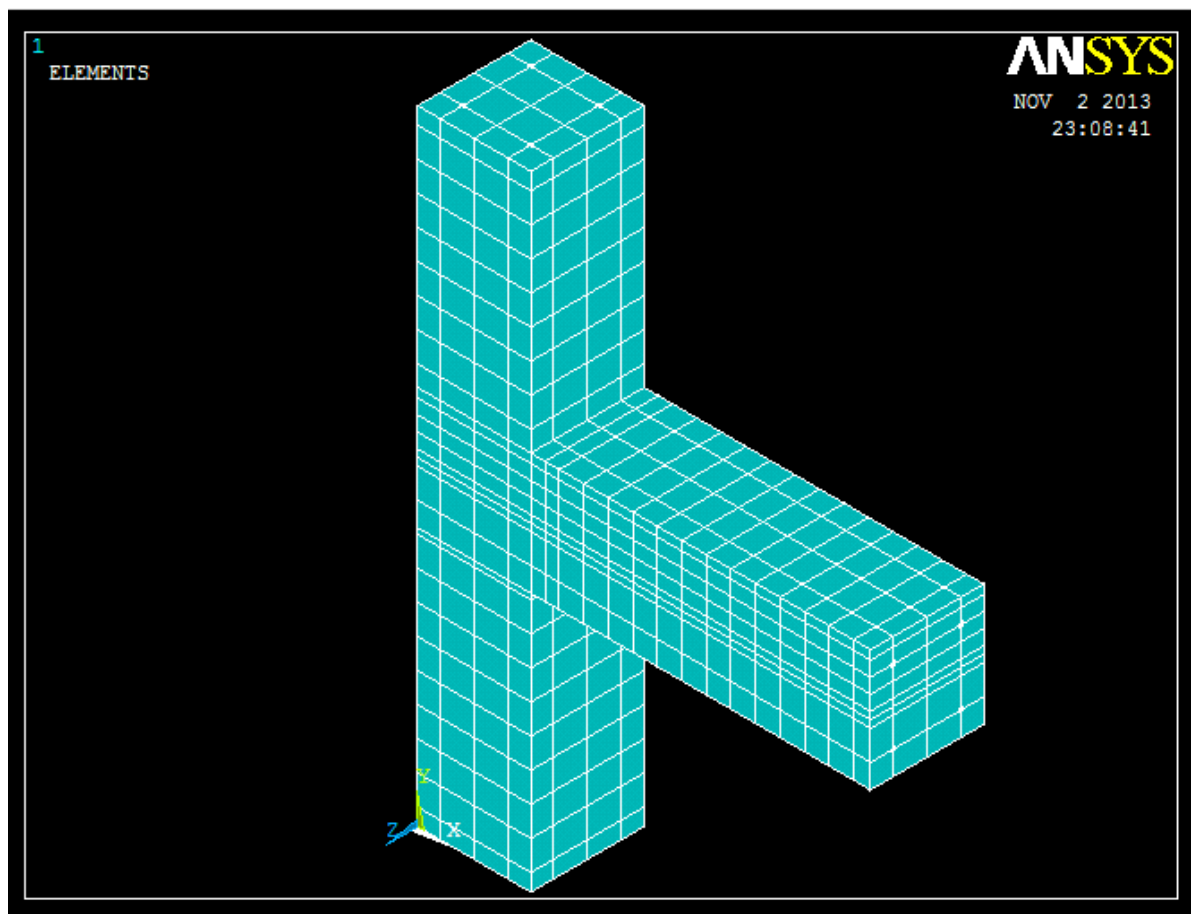

Figure 9c. Typical meshed Double Square Spring Shear Resistant System (DSSSRS) Specimen

\section{Results and Discussion}

ANSYS software was used to perform the non-linear analysis for the 3 beam-column specimens. For the purpose of developing a bending moment at the joint, the free end of the beam was subjected to a transverse static load. Load increments were done in steps till the controlled load of $20 \mathrm{KN}$ was achieved. A record was kept on the deflection of the beam-column connection at the end of the beam. The deflection values for the end of the beam for the conventionally designed specimen were 14.2 $\mathrm{mm}, 28.5 \mathrm{~mm}, 42.7 \mathrm{~mm}$ and $57.0 \mathrm{~mm}$ for $5 \mathrm{KN}, 10 \mathrm{KN}$, $15 \mathrm{KN}$ and $20 \mathrm{KN}$ loads respectively. A similar trend was repeated for "Single Square Spring Shear Resistance System" (SSSSRS) and "Double Square Spring Shear Resistance System" (DSSSRS) specimens. The deflection values resulting from the finite element analysis of control and improved specimens are shown in Figure 11 (a), Figure 11 (b), and Figure 11 (c) respectively. The deflection curve at the end of beam of the connections for control and improved specimens is shown in Figure 12. The stresses at various load intervals for control and improved specimens are demonstrated in table1. The deflection and energy absorption capacity of the control and improved specimens are compared against each other in Table 4. 
Table 4 illustrates a $10.70 \%$ difference between the deflection values of the beam-column connection specimen with "Single Square Spring Shear Resistant System" (SSSSRS) and the conventionally detailed specimen using Euro code where the higher deflection belongs to the conventional one. Also, a $11.75 \%$ difference between the deflection values of the beamcolumn connection specimen with "Double Square Spring Shear Resistant System" (DSSSRS) and the conventionally detailed specimen using Euro code where the higher deflection belongs to the conventional one. Furthermore, an $11.45 \%$ higher Energy Absorption Capacity was observed for the specimen beam-column connection using the "Single Square Spring Shear Resistant System" (SSSSRS) compared to that of conventionally detailed specimen and a $12.50 \%$ higher Energy Absorption Capacity was observed for the specimen beam-column connection using the "Double Square Spring Shear Resistance System" (DSSSRS) compared to the conventional one. Despite the significant differences between the conventional and the two new shear reinforcement system, several common advantages are listed for them which are as follows: saving the time and costs, incorporation of high level material properties, easy installation, solving the common problems of stirrups including being opened under loading and finally, buckling of the longitudinal bars.

Table 3. Deflection of Control and Improved Specimens

\begin{tabular}{|c|c|c|c|c|}
\hline Specimen & \multicolumn{4}{|c|}{ Deflection at end of the beam for the load of } \\
\hline ID & $5 \mathrm{KN}$ & $10 \mathrm{KN}$ & $15 \mathrm{KN}$ & $20 \mathrm{KN}$ \\
\hline CS & 14.2 & 28.8 & 42.7 & 57.0 \\
\hline SSSSRS & 12.7 & 25.5 & 38.2 & 50.9 \\
\hline DSSSRS & 12.6 & 25.2 & 37.7 & 50.3 \\
\hline
\end{tabular}

Table 4. Comparison between Deflection and Energy Absorption Capacity

\begin{tabular}{|c|c|c|c|c|}
\hline Specimen & Def. for the & \% reduction & E.A.C up to a & Def. of 10 \\
\hline ID & Load of $20 \mathrm{KN}$ & In deflection & 144.0 & In E.A.C \\
\hline CS & 57.0 & ------- & 127.5 \\
\hline SSSSRS & 50.9 & 10.70 & 126.0 & 11.45 \\
\hline
\end{tabular}

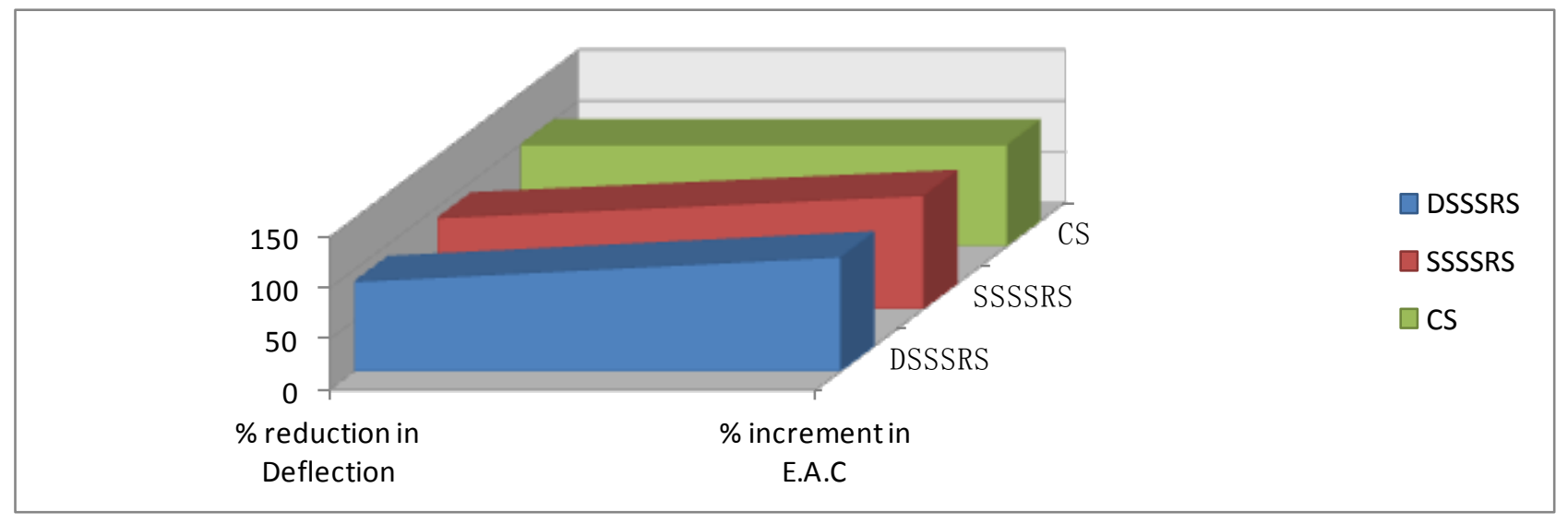

Figure 10. Comparison between Deflection and Energy Absorption Capacity

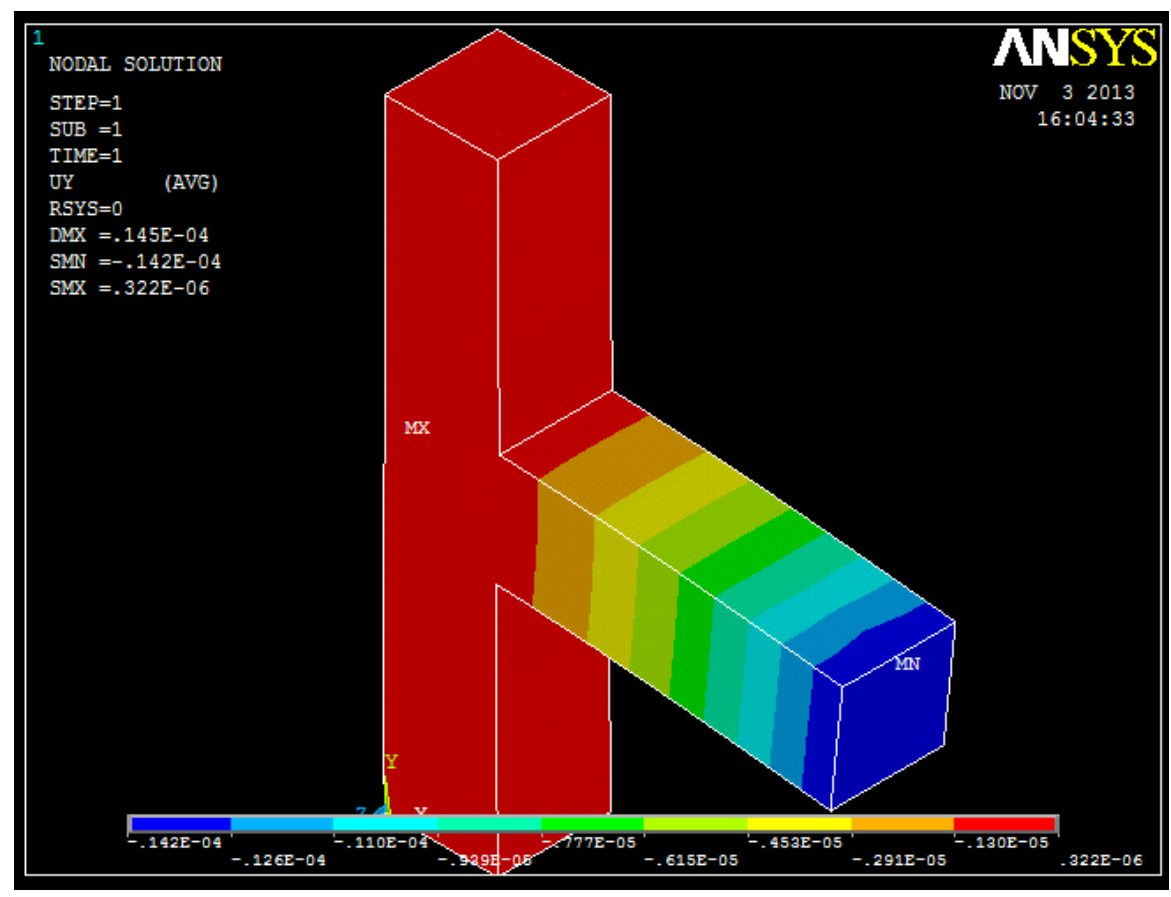

Figure 11 a. Typical View of Deflected Control Specimen 


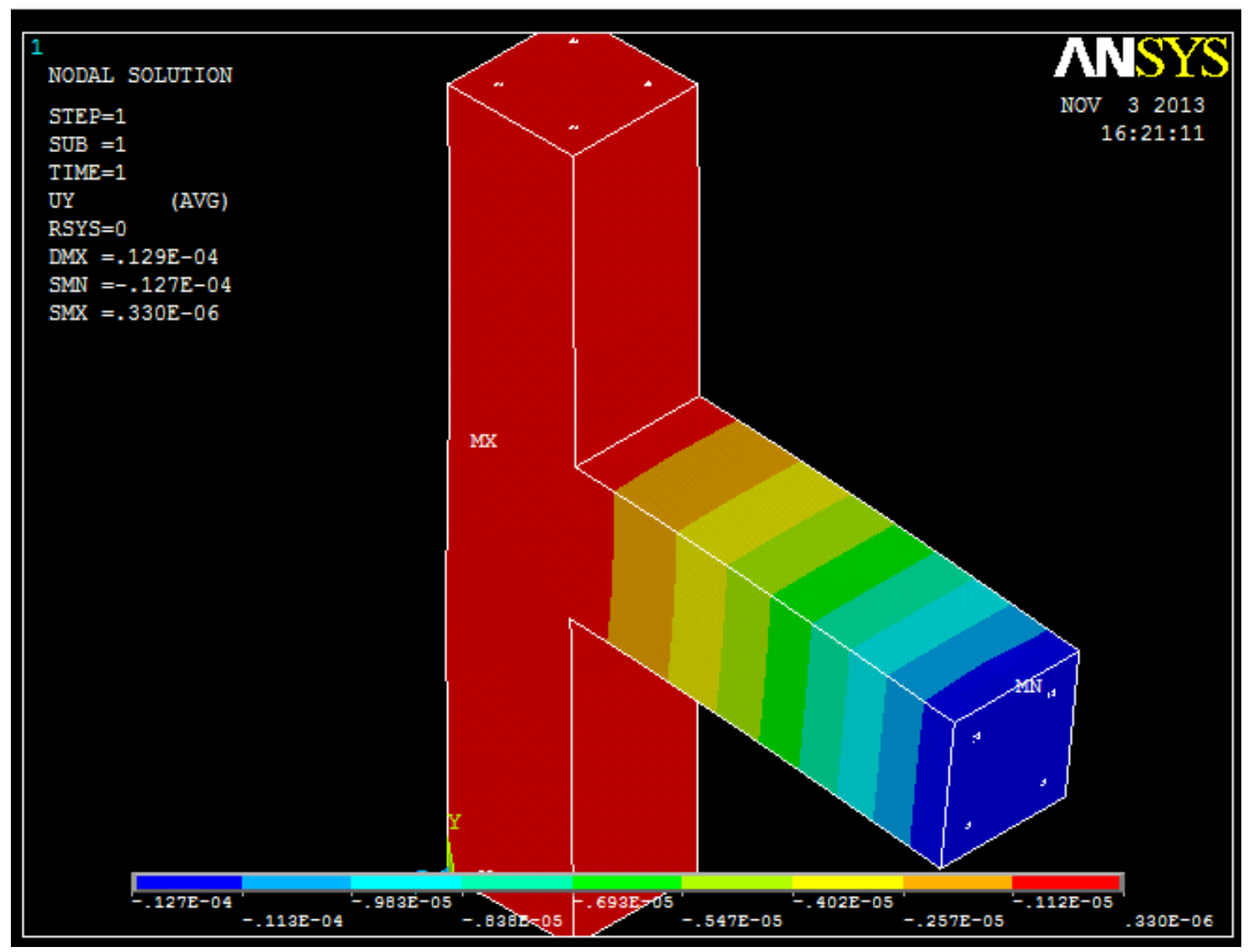

Figure 11 b. Typical View of Deflected Specimen with Single Square Spring Shear Resistant System (SSSSRS)

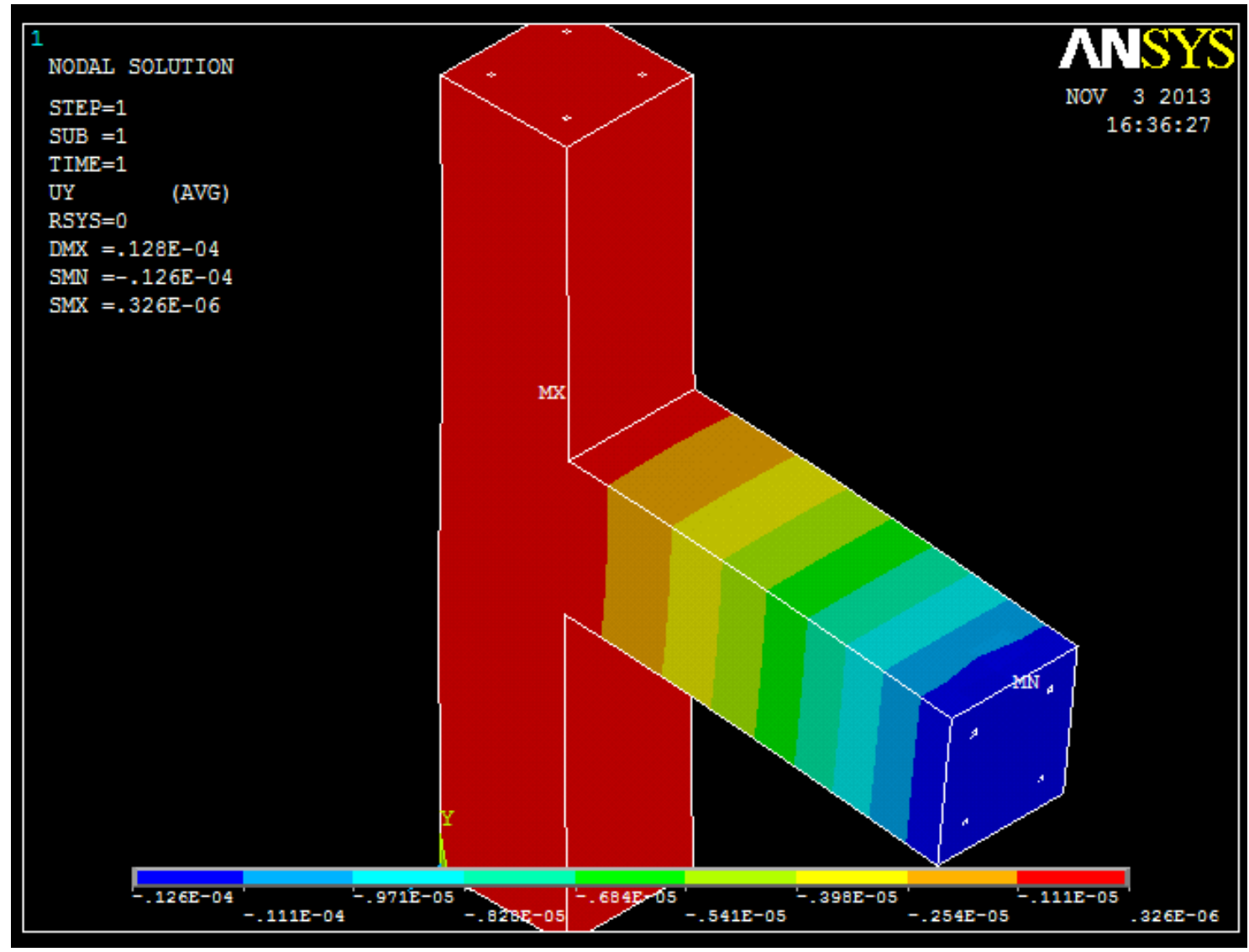

Figure 11 c. Typical View of Deflected Specimen with Double Square Spring Shear Resistant System (DSSSRS) 


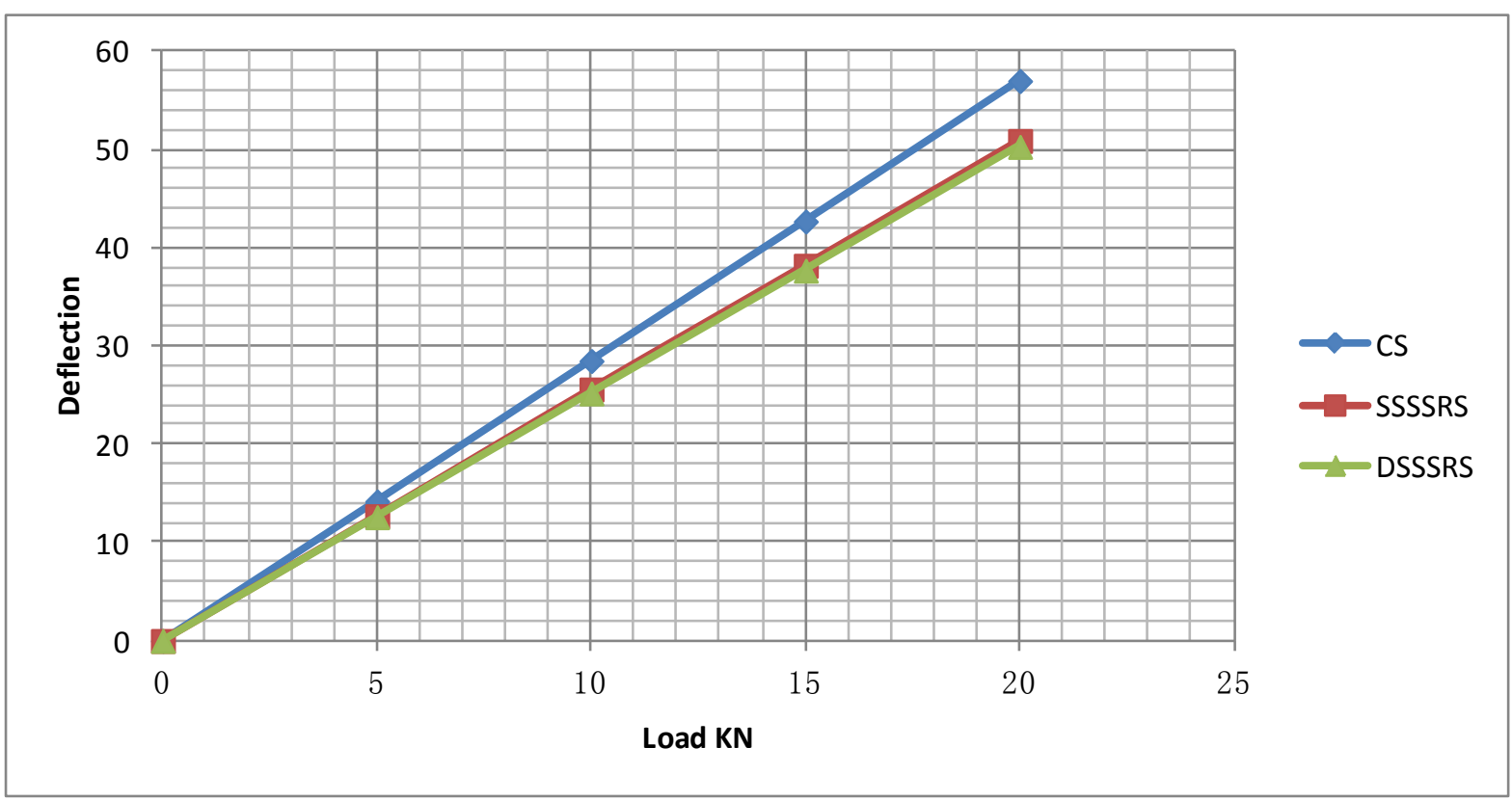

Figure 12. Load Deflection Curve for the Control and Improved Specimens

\section{Conclusions}

Based on the modelling and analysis results obtained from the finite element software ANSYS regarding the deflection and Energy Absorption Capacity of the two newly recommended beam-column connections namely "Single Square Spring Shear Resistant System" (SSSSRS) and "Double Square Spring Shear Resistant System" (DSSSRS) against the conventionally Euro Code based designed one, the following conclusions have been made:

1. The deflection of the beam-column connection specimen using "Single Square Spring Shear Resistant System" (SSSSRS) was found to be $10.70 \%$ lower than that of the specimen detailed conventionally.

2. The deflection of the beam-column connection specimen using "Double Square Spring Shear Resistant System" (DSSSRS) was found to be $11.75 \%$ lower than that of the specimen detailed conventionally.

3. The Energy Absorption Capacity of the beamcolumn connection specimen using "Single Square Spring Shear Resistant System" (SSSSRS) was found to be $11.45 \%$ higher than that of the specimen detailed conventionally.

4. The Energy Absorption Capacity of the beamcolumn connection specimen using "Double Square Spring Shear Resistant System" (DSSSRS) was found to be $12.50 \%$ higher than that of the specimen detailed conventionally.

\section{References}

[1] BinduK.R., Jaya K.P., 2008. Performance of Exterior Beam Column Joints with Cross Inclined Bars under Seismic Type Loading. Journal of engineering and applied science. vol. 7, pp 591-597.

[2] AppaRoa G.,Mahajan.M, Gangaram M., 2008. Performance of none seismically Designed RC Beam Column Joints Strengthen by
Various Schemes Subjected to Seismic Loads. Journal of structural engineering, vol. 35, pp 52-58.

[3] Devados Menon, Pradip Sarkar, Rajesh Agrawal, 2007, Design of RC Beam Column Joints Under Seismic Loading - A Review, Journal of structural engineering, vol. 33, pp 449-457.

[4] Jamal Shannag. M., Nabeela Abu,2005, Lateral Load Response of High Performance Fibre Reinforced Concrete Beam Column Joints, Journal of construction and building materials, vol. 19, pp 500-508.

[5] Willam,K. J. and Warnke, E. P. (1975), “Constitutive models for the triaxial behavior of concrete”, Proceedings of the International Assoc. for Bridge and Structural Engineering, vol. 19, pp. 1-30.

[6] Tavarez, F.A., (2001), "Simulation of Behavior of Composite Grid Reinforced Concrete Beams Using Explicit Finite Element Methods," Master's Thesis, University of Wisconsin-Madison, Madison, Wisconsin.

[7] Kachlakev, D.; Miller, T.; Yim, S., May, 2001, "Finite Element Modeling of Reinforced Concrete Structures Strengthened With FRP Laminates”, California Polytechnic State University, San Lius Obispo, CA and Oregon State University, Corvallis, OR for Oregon Department of Transportation, May.

[8] A.G.Tsonos, et.al., "Seismic resistance of Type 2 Exterior Beam column joints reinforced with inclined bars" The ACI structural Journal, Title No. 89-S1. 1992.

[9] Park, R and Paulay.T., "Behaviour of Reinforced Concrete BeamColumn Joints Under Cyclic Loading", Proceedings Fifth World Conference on Earthquake Engineering, Rome, Paper 88, pp. 10, 1973.

[10] Paulay, T., Park, R. and Birss, G.R., "Elastic Beam-Column Joints for Ductile Frames, Proceedings 7th World Confe-rence on Earthquake Engineering, Istanbul, Vol. 6, pp. 331-338, 1980.

[11] Thirugnanam.G.S., 2001, "Ductile behavior of SIFCON Structural member" Journals of Structural engineering, Vo-lume 28, No.1, pp 27-32, 2001.

[12] Wallace, et.al., 1998, "Use of Headed Reinforcement in BeamColumn Joints Subjected to Earthquake Loads" ACI Structural Journal,1998,Vol. 95 pp. 590-602, 1998.

[13] A.Murugesan et.al., "Ductile Behavior of Steel Fiber Rein-forced Concrete beam-column joints subjected to Cyclic loading", National Conference on Advances and Innovations in civil Engineering, MepcoSchlenk Engineering Col-lege, Sivakasi, pp. 27-33, 2009.

[14] Bonacci J, PantazoupoulouS., "Parametric investigation of joint mechanics". ACI Struct J Vol. 90, no. 1, pp. 61-71, 1993.

[15] Lakshmi G.A, Anjan Dutta, Deb S.K Grim, R.E., 2008. Numerical Study of Strengthening of Beam Column Joints under Cyclic Excitation Using FRP Composites, Journal of structural engineering, vol. 35, pp 59-65. 